\title{
Firearm Sales and the COVID-19 Pandemic
}

\author{
Bree Lang* \\ Matthew Lang ${ }^{\dagger}$
}

April 2020

\begin{abstract}
A record 3.7 million firearm background checks were completed in March, 2020, the month that the United States began responding to the COVID-19 pandemic. Using monthly state-level data, we show that the pandemic is associated with a 40 percent increase in the firearm background check rate. The COVID-19 effect is significantly greater than the increases in firearm sales associated with gun-buying events in the past, including the election of Barack Obama in 2008 and the Sandy Hook Elementary school shooting. During the COVID-19 pandemic, the increase in background checks in Republican-leaning states is statistically indistinguishable from the increase in Democrat-leaning states. The only other event that we explore where all states across the political spectrum react similarly in terms of firearm sales is following the 911 terrorist attacks. However, the magnitude of the increase in firearm background checks during the COVID-19 pandemic is approximately twice as large as the terrorist attacks. Our findings are relevant to public health officials concerned about the combination of more firearms and deteriorating mental health during the COVID-19 outbreak. At the same time, the non-partisan response in firearm purchases during the pandemic suggests that the divide between political parties may not be as wide as previously thought.
\end{abstract}

Keywords: COVID-19, firearm background checks, gun policy

JEL Codes: H75, I18

*University of California, Riverside, Department of Economics. Email: bree.lang@ucr.edu

†University of California, Riverside, Department of Economics. Email: matthew.lang@ucr.edu 


\section{Introduction}

In March, 2020, the month that the COVID-19 pandemic began in earnest in the United States, a record 3.7 million firearm background checks were completed (Federal Bureau of Investigation, 2020). The onset of the COVID-19 pandemic provides a unique opportunity to examine who purchases firearms when concerns about safety and uncertainty about the future are significantly heightened (Baker et al. 2020). Previously documented spikes in firearm sales occurred in the wake of mass shootings (Levine and McKnight, 2017, Studdert et al. 2017) and surrounding the 2008 election of Barack Obama (Depetris-Chauvin, 2015). This paper explores how the increase in firearm background checks during the COVID-19 pandemic differs from earlier surges in gun sales that are associated with future gun policy uncertainty.

Using a panel of monthly state observations between January, 1999 and April, 2020, we find that firearm background check rates increased by approximately 40 percent during the month of the COVID-19 outbreak. The effect is nearly twice as large as the increase in background checks following the 9-11 terrorist attacks. We also show that the recent spike in background checks was non-partisan, as the increase in firearm sales is not significantly different between the most Democrat-leaning (39 percent) and most Republican-leaning (44 percent) states.

We compare the effect of the COVID-19 pandemic to the changes in firearm background checks associated with elections and mass shootings (public shootings with 10 or more fatalities). In contrast to the nonpartisan response to COVID-19, Republican- and Democrat-leaning states have responded differently to past gun-buying events. Firearm background check rates in Republican-leaning states increase significantly more than in Democrat-leaning states in November of election years and in months of mass shootings, potentially due to the increase in gun policy uncertainty during these times. The relative difference between Republican- and Democrat-leaning states is larger following mass shootings that are associated with spikes in Google searches for terms about gun policy.

Our findings provide insight about the preferences for firearms across the political spectrum of the United States. Researchers have already shown that changes in future gun policy uncertainty and personal safety can lead to more firearm purchases. The effect of political uncertainty is studied by Depetris-Chauvin (2015), who finds that more firearms were purchased as the probability of Obama winning the election increased and this effect was stronger in states with looser gun laws. Depew and Swensen (2019) show that concealed carry permit applications increase after a homicide occurs and the relationship is driven by white, Republican males. The current paper confirms that both political uncertainty and threats to personal safety influence firearm purchases, and we extend these findings by showing how preferences for firearm purchases differ across political lines. Examining how firearm background check rates differ during COVID-19, elections and mass shootings also allows us to better understand the relative value citizens place on owning a gun when there is an increase in the overall level of uncertainty compared to buying a firearm because of uncertainty in gun policy. 
The results are relevant to those who are concerned about the mental health consequences of the COVID-19 pandemic (American Medical Association, 2020, Mannix et al., 2020, Reger et al., 2020). There is a consensus in the literature that firearm access is positively related to firearm suicide rates, often without a corresponding decrease in non-firearm suicide rates (Lang, 2013; Edwards et al. 2018, Balestra, 2018) 1 The unprecedented influx of firearms combined with worsening mental health resulting from quarantine measures (Pfefferbaum and North, 2020, Gunnell et al. 2020) has the potential to lead to an increase in suicide rates.

The findings are also of interest to policy makers. Gun policy is a divisive issue that cuts across party lines. A recent Pew Research Report (Gramlich and Schaeffer, 2019) finds that only 31 percent of Republicans are in favor of stricter gun laws, compared to 86 percent of Democrats. Although certain gun policy issues are more contentious than others, there is nearly universal support from both Republicans and Democrats for preventing people with mental illness from buying guns and running background checks on private sales. According to our results, the common ground across parties may go deeper than individual policy provisions. During the COVID19 pandemic, the increase in firearm sales between the most Republican-leaning and most Democrat-leaning states is not significantly different from each other, suggesting that when fear and uncertainty is heightened, a relatively large fraction of citizens turn to firearms for safety.

\section{Background and Data}

Firearm background checks reached record highs at the start of the COVID-19 outbreak Federal Bureau of Investigation, 2020) and have been shown to increase significantly during elections (Depetris-Chauvin, 2015) and following mass shootings (Levine and McKnight, 2017, Studdert et al., 2017). Our analysis estimates the effect of the COVID-19 outbreak on firearm sales and compares the effect to other gun-buying events that may increase gun policy uncertainty. Because the reasons to purchase a firearm may differ across political lines, we estimate the effects separately for Republican- and Democrat-leaning states. In this section, we identify how threats to safety ${ }^{2}$ such as the COVID-19 pandemic, along with elections and mass shootings are related to these motivations and provide predictions for how the response to these gun-buying events differ between Republican-leaning and Democrat-leaning states.

\section{A. Gun-Buying Events}

Safety has been a focal point of firearm ownership throughout the history of the United States. In an early draft of the Virginia Constitution, Thomas Jefferson highlighted the use of firearms for protection, writing, "No

\footnotetext{
${ }^{1}$ The relationship between firearm measures and crime is mixed. There is evidence that increasing firearm access and availability is associated with decreases in crime rates (Lott 2013. Gius 2019), increases in crime rates (Duggan 2001 Luca et al. 2017), increases some crimes and decreases others (Manski and Pepper, 2018) or has no effect on crime (Duggan et al.] 2011 Lang, 2016. Edwards et al. 2018).

"We use the term "threat to safety" to refer to general uncertainty that may invoke fear about a person's well-being. We do not define the exact nature of that uncertainty except that it is not directly related to uncertainty about gun policy.
} 
freeman shall ever be debarred the use of arms, within his own lands or tenements" (Jefferson, 1776). More recently, the 2015 National Firearm Survey reports that 63 percent of gun owners own a firearm for protection. Hunting was the next most common reason at 40 percent, followed by collecting, sporting use and protection against animals (Azrael et al., 2017). Kleck et al. (2011) find high gun ownership rates among past victims of crime and Hauser and Kleck (2013) show that those with fears of future victimization are more likely to purchase firearms $3^{3}$ The record number of firearm background checks completed during the COVID-19 outbreak in March, 2020 is consistent with the documented relationship between protection and firearm ownership. Because safety is being threatened during the outbreak, we expect the increase in firearms to be driven equally by individuals from all political backgrounds.

Another catalyst for spikes in firearm purchases is political uncertainty surrounding future gun policy (Depetris-Chauvin, 2015). A recent Pew Research survey finds that feelings towards gun policy are strongly correlated with political affiliation (Gramlich and Schaeffer, 2019). The survey reports that 69 percent of Republicans think gun laws are "about right" (49 percent) or should be "less strict" (20 percent) than they are today. Only 11 percent of Democrats believe that the current gun laws are "about right" and 4 percent think they should be "less strict". The involvement of the National Rifle Association (NRA) highlights the political divisiveness of gun policy. The NRA is often considered the most influential lobbying group in the United States (Rushe, 2018) and of the $\$ 6$ million in donations the NRA made to political campaigns in 2016, 98.4 percent were to candidates in the Republican party (Fisher et al. 2018). Because Republican party members are more likely to support current gun laws, we expect that increases in gun policy uncertainty will lead to more firearm purchases in Republican-leaning states, relative to Democrat-leaning states.

Mass shootings have also led to significant increases in firearm purchases. Prior to the COVID-19 pandemic, December, 2015 was the month with the highest number of firearm background checks on record (Federal Bureau of Investigation, 2020). In that month 14 people were killed and 22 were injured by two individuals in San Bernardino, CA. Levine and McKnight (2017) find that following the attack at Sandy Hook in December, 2012, there was also a substantial increase in firearm background checks. The increase in background checks following mass shootings can be driven by personal safety fears or concerns that stricter gun laws will be enacted in the near future. Luca et al. (2020) finds that mass shootings lead to an increase in proposed firearm legislation, but the laws that eventually become enacted are more likely to be gun loosening laws in states with Republican-controlled legislatures. A shooting event that either threatens safety or increases gun policy uncertainty is likely to increase firearm purchases for the average citizen in Republican-leaning states. Assuming Democrats do not respond to gun policy uncertainty, firearm sales are expected to increase in Democrat-leaning states after a mass shooting only if it causes an increased threat to safety.

\footnotetext{
${ }^{3}$ See Pierre 2019$)$ for an in-depth discussion of the role that fear plays in firearm purchases.
} 


\section{B. Google Trends in Gun Safety and Gun Policy}

In order to better understand how the COVID-19 pandemic, elections and mass shootings, are related to concerns about gun safety and gun policy, Figure 1 reports Google Trends data between January, 2007 and April, 2020. The data normalizes search terms on Google by setting the highest month of a term (or terms) at 100. When the index value in a month is 50, for example, the search intensity is half as much as the highest searched month. Google Trends data has been used often in academic research 4 but long-term comparisons of index values can be inaccurate, as the use of Google as a search engine has grown over time. However, localized spikes in relevant search terms can provide insight as to whether gun-buying events led to an increase in demand for guns due to safety or policy uncertainty. The solid blue line in Figure 1 shows the index value for the search term "gun for home", and proxies for interest in buying a gun for safety reasons. The dashed red line is the result for the search term "gun policy", and is meant to capture concerns about gun policy uncertainty ${ }^{5}$ In order to reduce distractions resulting from volatility in Figure 1, we take a simple two-month moving average of the index values 6

A number of gun-buying events are seen in Figure 1 and show how the response towards gun safety compares to gun policy during these events. The COVID-19 pandemic starting in March, 2020 is seen on the right side of Figure 1 Searches for "gun for home" reached their maximum level in March, 2020 and the search term was twice as popular in March, 2020 than in February, 2020. There is not a corresponding increase in searches for "gun policy" during the COVID-19 outbreak. Because Google searches for "gun for home" is noticeably higher than "gun policy" during the COVID-19 pandemic, it suggests that gun purchases made during this time were not due to uncertainty about future gun policy.

Four shooting events correspond with significant spikes in searches about guns in Figure 1. Following two of the events, Parkland, FL in February, 2018 and during the cluster of shootings that took place on July 28th (Gilroy, CA), August 3rd (El Paso, TX) and August 4th (Dayton, OH), searches about gun policy spike, but "gun for home" does not. Gun policy appears to be a larger concern than safety following these events. Consequently, we expect to observe an increase in firearm sales in Republican-leaning states, but not in Democrat-leaning states in response to the shootings in February, 2018 and the summer of 2019.

Two other shooting events are evident in Figure 1. Following the attacks at Sandy Hook in December, 2012 and in San Bernardino, CA in December, 2015, searches for "gun for home" and "gun policy" spiked. Assuming heightened concerns about safety are leading to firearm purchases after these events, we expect there to be an increase in firearm purchases in both Democrat-leaning and Republican-leaning states in December, 2012 and

\footnotetext{
${ }^{4}$ Google Trends are used in a similar manner in Levine and McKnight (2017). Tefft (2011), Stephens-Davidowitz (2014), Kearney and Levine (2015) and Berger et al. (2018) are just a few of many recent papers that incorporate Google Trends data directly into their empirical analysis.

${ }^{5}$ Many related search terms, such as "best gun for self defense", "gun for protection", "gun rights" and "gun control", yield similar patterns. These two terms were chosen due to the fact that the frequency of searches of both terms were similar and could be compared on a single index without being influenced by outliers. Choosing other search terms individually and overlaying the index values generates the same findings about how searches for gun safety and gun policy change over time.

${ }^{6}$ The "gun for home" value reported in April, 2020 is 88 since the April index is 76 and the March index is 100.
} 


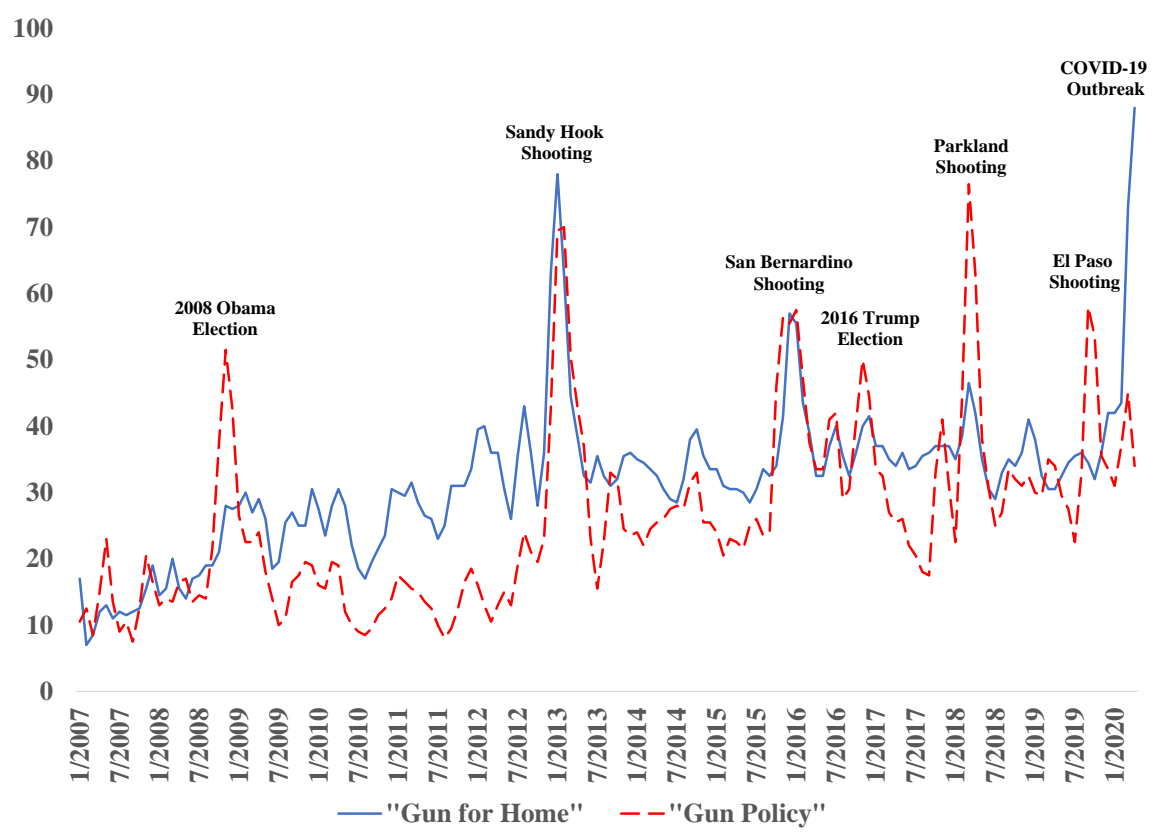

Figure 1: Index of Google Trends Searches that include "Guns for Home" and "Gun Policy" Notes: Reports the two-month moving average of Google Trend index values for the search terms "Gun for Home" in blue and "Gun Policy" in red. The index value of 100 occurred in March, 2020 for the search, "Gun for Home". On the figure, the value for "Gun for Home" in April, 2020 is reported as 88, which is the average of the March index value of 100 and the April index value of 76. The lower index value represents a lower search intensity, based on both the overall and relative intensity of the search terms.

December, 2015. Because these events are also correlated with searches about gun policy, it is possible that Republican-leaning states will purchase relatively more firearms than Democrat-leaning states. A number of other significant shooting events took place between 2007 and 2020. Although they do not appear to cause a spike in searches about guns, we examine many of them in our analysis below.

There are large increases in searches for gun policy during the 2008 and 2016 elections (the 2012 election is difficult to detect due to the Sandy Hook shooting in December, 2012). This is not surprising since gun policy may be at the forefront of elections, but there is no reason to believe there is an increased threat to safety during these months. Firearm purchases surrounding elections appear to be the result of gun policy uncertainty, suggesting that increases in firearm purchases during these months are likely to be driven by Republican-leaning states.

\section{Data}

In the next section, we empirically investigate how state firearm background check rates change during the onset of COVID-19, the 9-11 terrorist attacks, months of mass shootings and elections. Data on the exact number of firearm purchases that occur in a month are not available, but a close proxy exists. Since November, 1998, the 
Federal Bureau of Investigation (FBI) has published the number of monthly firearm background checks for every state. While this measure does not reflect firearm sales one-to-one, it has been shown to be a suitable proxy for firearm purchases (Lang, 2013) and used as both an independent (Lang, 2013, 2016; Levine and McKnight, 2017. Vitt et al., 2018) and dependent variable (Depetris-Chauvin, 2015, Levine and McKnight, 2017) in a number of studies. The FBI updates the data at the start of every month, allowing us to use data up to April, 30 2020:7

We first explore how firearm background checks change in response to the COVID-19 outbreak in March, 2020. Although the existence of the Coronavirus was known as early as December, 2019, it was not until March 16th that the United States banned foreign nationals from entering the country. Three days later, California became the first of 43 states and the District of Columbia to enact stay-at-home orders (Mervosh et al., 2020). The only other time a nationwide travel restriction was put in place in the United States since 1999 was following the 9-11 terrorist attacks (Donnelly, 2001). Both the COVID-19 and 9-11 terrorist attacks threatened personal safety across the United States and led to an increase in general uncertainty (Bloom, 2009), so we examine both of them in the analysis that follows.

Our analysis also explores the change in firearm background checks following shooting events, but mass shooting definitions vary considerably across data sources. In 2018, the Gun Violence Archive lists 340 mass shootings (Gun Violence Archive, 2020), the FBI had 27 active incident reports (Federal Bureau of Investigation, 2018) and Mother Jones reports 12 mass shootings (Follman et al. 2020). We mitigate these inconsistencies by defining a shooting event as a public shooting incident with 10 or more fatalities 8 It is possible that our strict mass shooting definition is missing out on gun-buying events, but not including these events is expected to bias our estimated results towards zero. Information about mass shootings are gathered and confirmed from a number of data sources (Stanford Geospatial Center, 2018, Follman et al., 2020, Gun Violence Archive, 2020. Federal Bureau of Investigation, 2018) and described in Table A.1.

The red and blue bars in Figure 2 show the average number of monthly firearm background checks per 1,000 from 1999 to 2020. Republican state averages are depicted in red and include all states that were won by the Republican presidential nominee in at least 3 of the 5 most recent presidential elections (2000 to 2016). The remaining states depicted in blue are Democrat-leaning states 9 The black line reports the number of mass shootings each year.

The average monthly background check rate for all states between 1999 and 2020 is 3.88 per 1,000, but there has been a noticeable rise in the background check rate over time. In red states, the average monthly firearm background check rate was near 3 per 1,000 between 1999 and 2007. The background check rate in red states doubled between 2007 and 2013 and is at 8 per 1,000 in 2020, higher than any previous year's monthly

\footnotetext{
${ }^{7}$ We remove Kentucky from the sample because starting in 2006, Kentucky began running monthly background checks on all concealed carry permit holders, regardless of whether or not a firearm was purchased. The District of Columbia is also dropped from the analysis since we use the natural log of background checks in the next section and DC has multiple months with zero background checks. Including both states in the analysis does not change the implications of the results.

${ }^{8}$ Luca et al. (2020) show that the media coverage following mass shootings with 10 or more fatalities is significantly higher than those with 4 to 5 or 6 to 9 fatalities.

${ }^{9}$ In the analysis below, we define Republican and Democrat states based on the outcome of the most recent presidential election.
} 


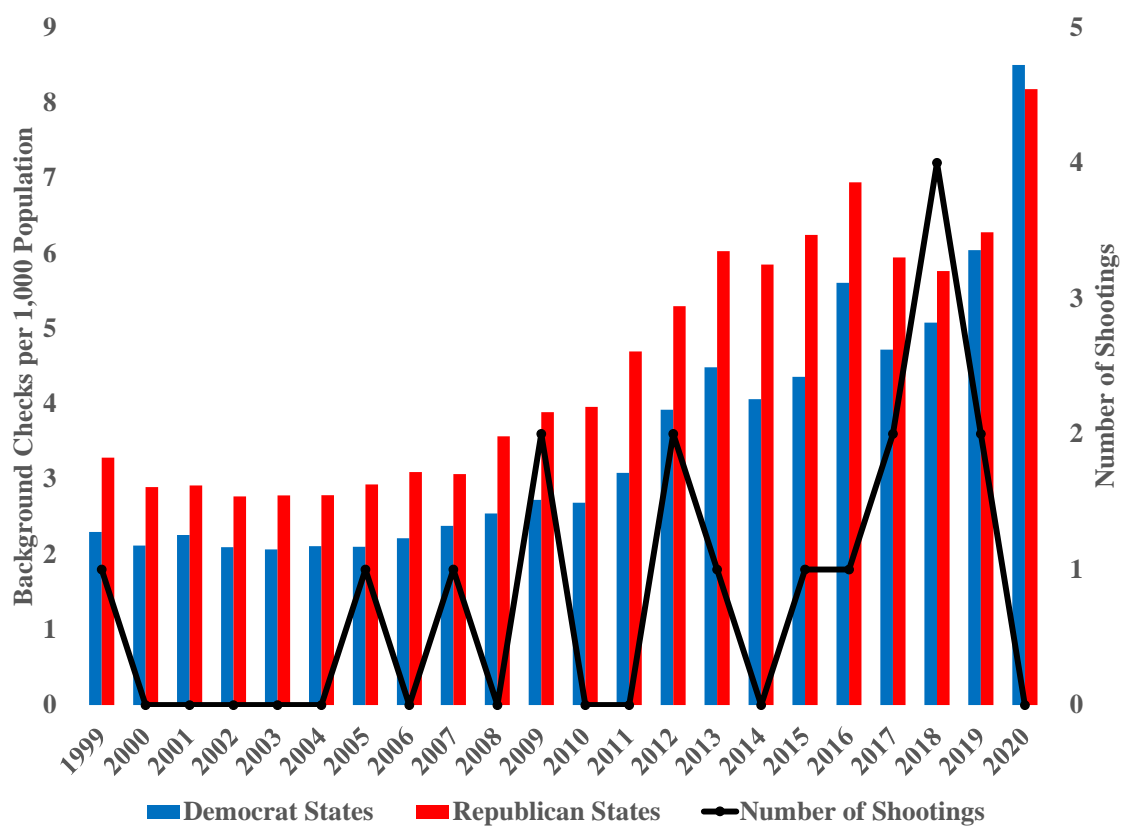

Figure 2: Average Monthly Background Checks per 1,000 Population and Mass Shootings by Year Notes: Reports the average monthly background check rate per 1,000 of population for each year. Republican states are defined as those in which the Republican presidential nominee won in at least 3 of the 5 most recent presidential elections (2000 to 2016 ). Mass shootings are defined as public shootings in which there were 10 or more fatalities.

average. Background check rates in blue states were lower than red states between 1999 and 2019, but started to converge with red states in 2016. In 2020, the background check rate in blue states is higher than red states.

Figure 2 shows an increase in the frequency of mass shootings over time. Since 1999, there have been 17 shooting events with 10 or more fatalities. Between 1999 and 2008, there were two mass shootings. In 2018, there were four mass shootings. Firearm background checks and mass shootings have both grown over time, but firearm background check rates reached record highs in 2020 and the only gun-buying event we document in the year is the COVID-19 pandemic.

Our panel data set below consists of monthly state-level firearm background checks, population estimates ${ }^{10}$ election information (Federal Election Commission, 2020) and binary variables equal to one in the month of the COVID-19 outbreak (March, 2020), the month of September, 2001, months that a mass shooting occurred and election months.

\footnotetext{
${ }^{10}$ Population estimates for July of every year are available through the Census (United States Census Bureau, 2020). We linearly interpolate monthly population values from the July estimates.
} 


\section{Empirical Strategy and Results}

\section{A. Empirical Strategy}

In this section, we estimate how large scale events alter the gun buying behavior of US citizens. To serve as a foundation for our empirical framework, consider a difference-in-differences model that regresses monthly background checks per population on binary variables that indicate whether or not an event occurred in that month:

$$
\begin{array}{r}
\ln (\text { BGC } / \text { Pop })_{i m t}=\beta_{1} \text { SafetyEvent }_{m t}+\beta_{2} \text { NovemberElection }_{m t}+ \\
\beta_{3} \text { Shooting }_{m t}+\gamma_{i}+\psi_{m}+\tau_{t}+\epsilon_{i m t} .
\end{array}
$$

The dependent variable $\ln (B G C / P o p)_{i t m}$ represents the natural log of the number of firearm background checks completed in state $i$ in month $m$ of year $t$, divided by the population. The independent variables are binary variables that are equal to one if an event occurred during month $m$ of year $t$. The events are categorized into those that uniquely threaten the safety of citizens, November of election years and public shootings with 10 or more fatalities. The variables $\gamma_{i}, \psi_{m}$ and $\tau_{t}$ represent state, month and year fixed effects.

The resulting estimates from specification (1) indicate the level differences in the background check rate in months that experience potential gun-buying events relative to months without events. Because we want to estimate the reaction to a particular event, we take the difference in equation (1) between month $m$ and month $m-1$. This yields the following specification, where $\Delta$ indicates the monthly difference:

$$
\begin{array}{r}
\Delta \ln (\text { BGC } / \text { Pop })_{\text {imt }}=\beta_{\Delta 1} \Delta \text { SafetyEvent }_{m t}+\beta_{\Delta 2} \Delta \text { NovemberElection }_{m t}+ \\
\beta_{\Delta 3} \Delta \text { Shooting }_{m t}+\pi_{i}+\psi_{\Delta m}+\Delta \tau_{t}+\mu_{i m t} .
\end{array}
$$

The estimates in specification (2) provide a slightly different interpretation than the estimates from specification (1). The estimated coefficient $\beta_{\Delta 1}$ measures how the change in the background check rate differs between months in which an event that threatens safety occurs, relative to months without such an event. The coefficients $\beta_{\Delta 2}$ and $\beta_{\Delta 3}$ have a similar interpretation with November elections and shooting events.

The fixed effects in specification (2) are also subject to a different interpretation. Differencing the specification removes the original state fixed effect because it was constant for states across months. We add a new state fixed effect, $\pi_{i}$, which controls for state-specific trends in background checks.

The altered monthly fixed effect now controls for potential gun-buying shocks that may occur every year in the same month. The altered year fixed effect represents an average monthly trend that is common for 
all states in a given year. The controls for trends in specification 2 provides a better estimate of how the population is reacting to a specific event, while accounting for the general levels that are present around the time of that event ${ }^{11}$ In additional regressions, we estimate the potential differences in gun buying reactions between Democrat- and Republican-leaning states by interacting each of the independent variables of interest with a binary variable equal to one if the Republican presidential nominee won the state in the most recent election 12

The identifying assumption is that the occurrence of a gun-buying event is unrelated to monthly changes in state background check rates that are not captured by state-specific trends in background checks, seasonal recurring shocks in firearm purchases and monthly trends across all states. The predictable timing of election months opens up the possibility that other biennial events are influencing firearm background checks and potentially biasing the election coefficients. While it may not be the election itself leading to an increase in firearm sales during these months, most channels that could influence firearm purchases surrounding elections is likely to involve elements of gun policy. There is less concern about potential endogeneity arising from the COVID-19 pandemic or shooting events, as the exact timing of these events appears to be random.

\section{B. Results}

The results from specification (2) are reported in the first column of Table II. This specification shows the relationship between firearm background check rates and gun-buying events for all states, regardless of their political affiliation. The first reported coefficient suggests that the onset of the COVID-19 outbreak in the US in March, 2020 was associated with a 41.7 percent increase in background checks. The COVID-19 surge was more than twice as large as the surge that took place during September, 2001, which is estimated at 19.5 percent. The increase in firearm background check rates during COVID-19 was seven times more than the increase in election months (5.9 percent) and almost six times more than the increase following mass shootings (7.1 percent).

The second column of Table 1 reports the coefficients for Democrat- and Republican-leaning states separately. The first two rows show that the increase in background check rates associated with the COVID-19 pandemic was not statistically different between Democrat-leaning (38.6 percent) and Republican-leaning states (44.0 percent). There is also not a significant difference in the increase in firearm background checks between Democratand Republican-leaning states following the 9-11 terrorist attacks, an event we presume increased uncertainty surrounding safety, but did not directly increase gun policy uncertainty. During elections or following mass shootings, firearm background checks increased significantly more in Republican-leaning states than Democratleaning states.

In column (3), we find that the differential response between Republican- and Democrat-leaning states

\footnotetext{
${ }^{11}$ Estimating specification (1) yields results that have the same implications to those estimated with specification (2).

${ }^{12}$ The results below are not sensitive to alternative rankings of political leanings, such as using the share of votes for the Republican nominees in the House of Representatives elections.
} 
Table I: Effect of Safety and Policy Uncertainty Events on Background Checks for Gun Purchases: Blue vs. Red States

Dependent Variable: Monthly Change in $\ln$ (Background Checks/Population)

\begin{tabular}{|c|c|c|c|c|}
\hline & & & & \\
\hline & $(1)$ & $(2)$ & $(3)$ & $(4)$ \\
\hline \multirow[t]{2}{*}{ COVID-19: March 2020} & $0.417^{* * *}$ & $0.386^{* * *}$ & $0.388^{* * *}$ & $0.380 * * *$ \\
\hline & $(0.0466)$ & $(0.0652)$ & $(0.0651)$ & $(0.0795)$ \\
\hline \multirow[t]{2}{*}{ X Majority Vote Republican } & & 0.0541 & 0.0545 & 0.0673 \\
\hline & & $(0.0708)$ & $(0.0708)$ & $(0.0933)$ \\
\hline \multirow[t]{2}{*}{ 9-11: September 2001} & $0.195^{* * *}$ & $0.219^{* * *}$ & $0.221^{* * *}$ & $0.224^{* * *}$ \\
\hline & $(0.0240)$ & $(0.0546)$ & $(0.0548)$ & $(0.0582)$ \\
\hline \multirow[t]{2}{*}{ X Majority Vote Republican } & & -0.0490 & -0.0491 & -0.0545 \\
\hline & & $(0.0747)$ & $(0.0748)$ & $(0.0807)$ \\
\hline \multirow[t]{2}{*}{ Election Year November } & $0.0592 * * *$ & $0.0307^{* *}$ & $0.0405 * * *$ & $0.0393^{* * *}$ \\
\hline & $(0.00692)$ & $(0.0141)$ & $(0.0128)$ & $(0.0138)$ \\
\hline \multirow[t]{2}{*}{ X Majority Vote Republican } & & $0.0629 * *$ & $0.0605^{* *}$ & $0.0631^{* *}$ \\
\hline & & $(0.0240)$ & $(0.0242)$ & $(0.0266)$ \\
\hline \multirow[t]{2}{*}{ Shooting Event } & $0.0705^{* * *}$ & $0.0481^{* * *}$ & & \\
\hline & $(0.00798)$ & $(0.00958)$ & & \\
\hline X Majority Vote Republican & & $0.0475^{* * *}$ & & \\
\hline & & $(0.0110)$ & & \\
\hline \multirow[t]{2}{*}{ Shooting Event before November 2008} & & & 0.0282 & 0.0333 \\
\hline & & & $(0.0192)$ & $(0.0215)$ \\
\hline \multirow[t]{2}{*}{ X Majority Vote Republican } & & & $-0.0492^{* *}$ & $-0.0615^{* *}$ \\
\hline & & & $(0.0236)$ & $(0.0271)$ \\
\hline \multirow[t]{2}{*}{ Shooting Event during Obama Presidency } & & & $0.0727^{* * *}$ & $0.0696^{* * *}$ \\
\hline & & & $(0.0116)$ & $(0.0132)$ \\
\hline \multirow[t]{2}{*}{ X Majority Vote Republican } & & & $0.0510^{* * *}$ & $0.0592^{* * *}$ \\
\hline & & & $(0.0127)$ & $(0.0160)$ \\
\hline \multirow[t]{2}{*}{ Shooting Event during Trump Presidency } & & & $0.0223^{* *}$ & 0.0133 \\
\hline & & & $(0.00899)$ & $(0.00919)$ \\
\hline \multirow[t]{2}{*}{ X Majority Vote Republican } & & & $0.0737^{* * *}$ & $0.0895^{* * *}$ \\
\hline & & & $(0.0136)$ & $(0.0135)$ \\
\hline Binary for Presidential Vote Majority Republican & $\mathrm{N}$ & $\mathrm{Y}$ & $\mathrm{Y}$ & $\mathrm{Y}$ \\
\hline Presidency Fixed Effects & $\mathrm{N}$ & $\mathrm{N}$ & $\mathrm{Y}$ & $\mathrm{Y}$ \\
\hline State by Year Fixed Effects & $\mathrm{N}$ & $\mathrm{N}$ & $\mathrm{N}$ & $\mathrm{Y}$ \\
\hline
\end{tabular}

Note: Stars following coefficients represent $p$-values less that $0.10\left(^{*}\right), 0.05(* *)$ and $0.01(* * *)$. Sample size in all regressions 12,495 state-month observations. Every column includes year, state and month fixed effects. Variable Republican Pres. Majority is binary and equal to one if percentage of the state that voted for the Republican candidate in the most presidential election was greater than the percentage that voted for the Democrat candidate. Presidency fixed effects include three binary variables for the years in which Bush, Obama and Trump were each in office. Robust standard errors are reported in parentheses and clustered by state.

following mass shootings is driven by mass shootings after 2008. The concerns surrounding gun rights in the wake of mass shootings appear to be growing over time, especially in Republican-leaning states 13 The change in the reaction to shooting events that we observe in column (3) is consistent with the Google Trend data in Figure 1 showing that the first spike in searches for gun policy did not happen until the election of Barack Obama.

Column (4) of Table I addresses concerns that the estimated differences between Democrat- and Republican-

\footnotetext{
${ }^{13}$ The difference is potentially related to changes in the national conversation about guns and gun rights. According to data from the Senate Office of Public Records, the National Rifle Association has spent substantially more on lobbying since 2008. The average annual spending was equal to $\$ 1.7$ million between 1998 and 2008. Between 2009 and 2019, the annual average spending was $\$ 3.4$ million (Center for Responsive Politics, 2020).
} 
leaning states are driven by differing trends over time. We add state by year fixed effects to allow for state-specific trends that can evolve over time. None of the coefficients are meaningfully altered.

Table II: Effect of Safety and Policy Uncertainty Events on Background Checks for Gun Purchases: Across the Political Spectrum

\begin{tabular}{|c|c|c|}
\hline \multirow[b]{2}{*}{ VARIABLES } & \multicolumn{2}{|c|}{$\begin{array}{l}\text { Dependent Variable: Monthly Change } \\
\text { in } \ln \text { (Background Checks/Population) }\end{array}$} \\
\hline & $(1)$ & $(2)$ \\
\hline \multirow[t]{2}{*}{ COVID-19: March 2020} & $0.389^{* * *}$ & $0.383^{* * *}$ \\
\hline & $(0.0711)$ & $(0.0893)$ \\
\hline \multirow[t]{2}{*}{ X Moderate States } & 0.0464 & 0.0577 \\
\hline & $(0.0785)$ & $(0.105)$ \\
\hline \multirow[t]{2}{*}{ X Most Republican States } & 0.0478 & 0.0558 \\
\hline & $(0.0969)$ & $(0.122)$ \\
\hline \multirow[t]{2}{*}{ 9-11: September 2001} & $0.182^{* * *}$ & $0.186^{* *}$ \\
\hline & $(0.0651)$ & $(0.0700)$ \\
\hline \multirow[t]{2}{*}{ X Moderate States } & 0.0609 & 0.0556 \\
\hline & $(0.0863)$ & $(0.0937)$ \\
\hline \multirow[t]{2}{*}{ X Most Republican States } & -0.0474 & -0.0570 \\
\hline & $(0.0827)$ & $(0.0902)$ \\
\hline \multirow[t]{2}{*}{ Election Year November } & 0.00370 & -0.000927 \\
\hline & $(0.0243)$ & $(0.0262)$ \\
\hline \multirow[t]{2}{*}{ X Moderate States } & $0.0933^{* * *}$ & $0.101^{* * *}$ \\
\hline & $(0.0306)$ & $(0.0331)$ \\
\hline \multirow[t]{2}{*}{ X Most Republican States } & $0.100^{* * *}$ & $0.108^{* * *}$ \\
\hline & $(0.0361)$ & $(0.0397)$ \\
\hline \multirow{2}{*}{ Shooting Event before November 2008} & $0.0488^{*}$ & $0.0582^{* *}$ \\
\hline & $(0.0245)$ & $(0.0281)$ \\
\hline \multirow[t]{2}{*}{ X Moderate States } & $-0.0673^{* * *}$ & $-0.0826^{* * *}$ \\
\hline & $(0.0245)$ & $(0.0277)$ \\
\hline \multirow[t]{2}{*}{ X Most Republican States } & $-0.0675^{* *}$ & $-0.0835^{* *}$ \\
\hline & $(0.0302)$ & $(0.0348)$ \\
\hline \multirow[t]{2}{*}{ Shooting Event during Obama Presidency } & $0.0633^{* * *}$ & $0.0579^{* * *}$ \\
\hline & $(0.0150)$ & $(0.0176)$ \\
\hline \multirow[t]{2}{*}{ X Moderate States } & $0.0408 * * *$ & $0.0482^{* *}$ \\
\hline & $(0.0150)$ & $(0.0188)$ \\
\hline \multirow[t]{2}{*}{ X Most Republican States } & $0.0596^{* * *}$ & $0.0712^{* * *}$ \\
\hline & $(0.0167)$ & $(0.0206)$ \\
\hline \multirow[t]{2}{*}{ Shooting Event during Trump Presidency } & $0.0182^{* *}$ & 0.00819 \\
\hline & $(0.00882)$ & $(0.00817)$ \\
\hline \multirow[t]{2}{*}{ X Moderate States } & $0.0714^{* * *}$ & $0.0879 * * *$ \\
\hline & $(0.0142)$ & $(0.0144)$ \\
\hline \multirow[t]{2}{*}{ X Most Republican States } & $0.0825^{* * *}$ & $0.0980^{* * *}$ \\
\hline & $(0.0124)$ & $(0.0106)$ \\
\hline Presidency Fixed Effects & $\mathrm{Y}$ & $\mathrm{Y}$ \\
\hline State by Year Fixed Effects & $\mathrm{N}$ & $\mathrm{Y}$ \\
\hline
\end{tabular}

A robust finding throughout Table $\rrbracket$ is that the COVID-19 pandemic led to an increase in background check 
rates that was significantly larger than the 9-11 attacks, elections and mass shootings. Unlike elections and mass shootings, the increase in firearms following COVID-19 was statistically similar between Republican-leaning and Democrat-leaning states. To confirm the non-partisan influence of COVID-19, we use a finer stratification of political leanings in Table II. We create this new stratification by calculating the average share of each state that voted Republican in every presidential election from 2000 to 2016 and classify the states into terciles based on that ranking 14

The coefficients related to the COVID-19 pandemic and 9-11 attacks in the first column of [I] have the same implications as those found in Table II. The background check rate increases substantially in the states that most often vote for the Democratic presidential nominee. The change in background check rates in the most Democrat-leaning states are not significantly different from states in the middle of the political spectrum or the most Republican-leaning states. Similar to the initial results in Table I] the increase in background checks during the COVID-19 outbreak are approximately twice as large as the increase following the 9-11 attacks.

The rest of the results in Table II yield similar conclusions as the previous set of results in Table I] Firearm background check rates in the moderate and most Republican states increase significantly more than the most Democrat-leaning states during elections and following mass shootings after 2008 15 Consistent with Table I the increase in background check rates during the COVID-19 outbreak (38.9 to 43.7 percent) is significantly larger in magnitude than the increase during elections ( 0.3 percent to 10 percent) or mass shootings (up to 12.3 percent).

According to Table II] when there is a potential gun-buying event associated with gun policy uncertainty, such as elections or mass shootings, the reaction of states depends on their political leaning. When there is an increased threat to personal safety that does not involve gun policy uncertainty, such as the COVID-19 pandemic, the increase in firearm purchases is similar across all states. The finding highlights the non-partisan role that safety plays in the decision to purchase a firearm.

We examine whether the Google Trends data from Figure 1 aligns with political leanings within our analysis in Table III. Since 2007, the only time that searches for "gun for home" spiked but "gun policy" did not was during the COVID-19 outbreak. After the Parkland and El Paso shooting events and elections, searches for "gun policy" increased, but "gun for home" did not. Both search terms spiked following the shootings at Sandy Hook and in San Bernardino. The differences in the intensity of search terms associated with the events guide how we expect Republican- and Democrat-leaning states to respond.

In Table [II], we report estimates from one regression in the first two columns. The coefficient in the first column is the estimate associated with Democrat-leaning states and the second column reports the Republican interaction term. Similar to Table [] we define states as Republican- or Democrat-leaning based on whether the Republican share of the presidential vote was greater than the Democrat share in the most recent presidential

\footnotetext{
${ }^{14}$ Similar conclusions are reached when splitting states into quartiles.

${ }^{15}$ We repeat this analysis in column (2) of Table II and include state by year fixed effects to account for potential state-specific trends. The results are not meaningfully altered by its inclusion.
} 
Table III: Effect of Safety and Policy Uncertainty Events on Background Checks for Gun Purchases: Connecting to Google Trends Searches

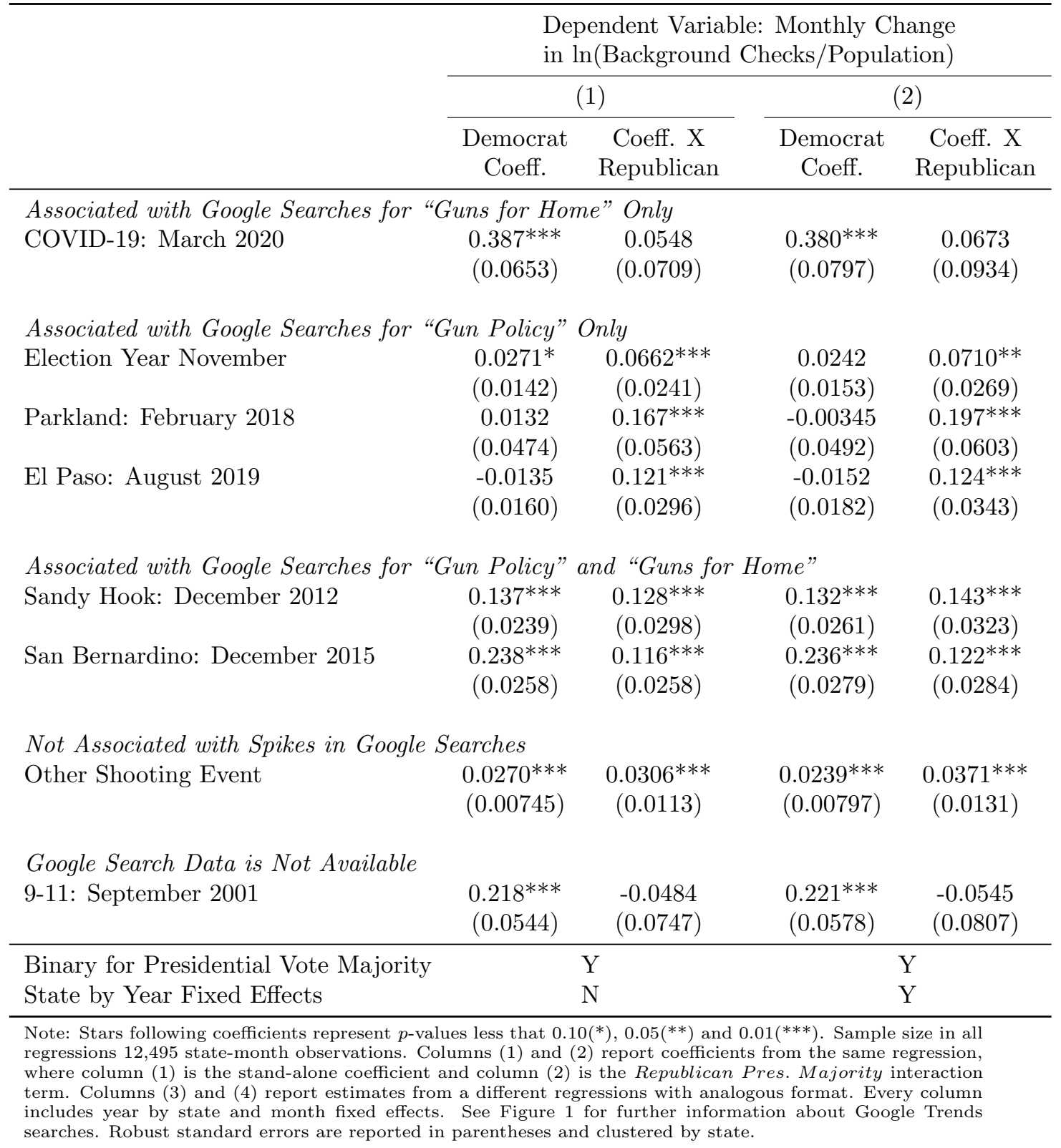

election.

Consistent with the predictions from the Google Trends data, we continue to find that the increase in background check rates during the COVID-19 pandemic is large and does not differ significantly between Democrat-leaning (38.7 percent) and Republican-leaning (44.2 percent) states. Predictions about election months and the Parkland and El Paso shooting events are confirmed in the second panel of Table III. Following these events, firearm background check rates increased significantly in Republican-leaning states, but not in Democrat-leaning states. The magnitude of the increase in background checks in Republican-leaning states following the Parkland shooting is 18 percent. While this is a large effect relative to previous results, it remains significantly less than the 44.2 percent increase during the COVID-19 outbreak. 
In the third panel of Table III] we show the results from the shooting events in Sandy Hook and San Bernardino, which were associated with increases in searches for both "gun for home" and "gun policy". The results support the predictions, as there is a significant increase in firearm background checks in all states following the two shootings, with a significantly larger increase in Republican-leaning states. The increase in the background check rate in Republican-leaning states following the San Bernardino shooting was 35.4 percent, which is larger than other shooting events, but lower than the increase associated with the COVID-19 pandemic $(\mathrm{p}$-value $=0.13)$.

We also estimate the effects of mass shootings that are not associated with spikes in Google searches. The results show that the increase in firearm background checks in both Republican- and Democrat-leaning states are significant but small in magnitude, relative to the other shooting events. In the last panel of Table III], we show the effect of the 9-11 attacks, which took place before Google search data is available. Consistent with earlier results, there is an increase in background checks in all states following the attacks and there is not a significant difference in the increase between Democrat- and Republican-leaning states. In the third and fourth columns of Table III. we include state by year fixed effects to account for potential state-specific trends and the results are not meaningfully altered.

These results suggest that there are two primary motivators to purchasing a firearm. One is a response to safety and the other is a response to a perceived loss of the right to own a gun. The relatively large increase in firearm sales in all states during the COVID-19 outbreak, the 9-11 terrorist attacks and following mass shootings associated with Google searches for gun safety, suggests that owning a firearm for protection is important to a significant portion of the population.

\section{Discussion and Conclusion}

The COVID-19 pandemic provides an opportunity to examine an unprecedented increase in firearm purchases caused by a threat to safety that is unrelated to gun policy uncertainty. We find that the COVID-19 outbreak increased firearm sales more than any previous gun-buying event and the effect was just as large in Republicanleaning states as Democrat-leaning states. Following the 9-11 terrorist attacks, another threat to personal safety that presumably did not have a corresponding increase in gun policy uncertainty, firearm background check rates also increased across all states.

Comparing the results from the COVID-19 pandemic to elections and mass shootings provide a clearer picture of the demand for firearms in the United States. Our results indicate that increases in uncertainty due to safety threats, such as the COVID-19 outbreak, lead to a significantly larger increase in firearm sales than elections or mass shootings. This highlights the importance of owning a firearm for protection and safety. The connection between firearms and safety has been part of the gun policy discussions since the 1700s and continues to be a focal point today. Prior to this study, there was evidence that gun owners valued guns for protection, 
but the COVID-19 pandemic is the first gun-buying event since the 9 -11 terrorist attacks that did not involve a corresponding increase in gun policy uncertainty.

The recent increase in firearms during the COVID-19 pandemic may lead to negative health outcomes. There is anecdotal evidence that many of the purchases being made during the pandemic are by first-time gun owners (Beckett, 2020), who may not be accustomed to handling a firearm. Levine and McKnight (2017) show that following the Sandy Hook shooting, accidental gun deaths increased. Our results suggest that firearm background checks increased by 150 percent more during the COVID-19 pandemic compared to the month of Sandy Hook. Another public health concern arises when combining increased access to firearms with worsening mental health resulting from stay-at-home orders (Pfefferbaum and North, 2020). There is strong evidence that the availability of firearms can lead to higher firearm suicide rates Lang, 2013, Edwards et al., 2018, Balestra, 2018) and it is possible that the COVID-19 pandemic will strengthen this relationship.

Despite the health concerns that can arise from an influx of firearms, the results provide optimism about future gun policy. Although feelings about current gun policy are correlated with political affiliation, the divide between political parties may not be as wide as previously thought. Gun owners have been referencing safety and protection as a primary reason for owning guns for many years. Prior to the COVID-19 pandemic, identifying how non-gun owners would respond to an increased threat to personal safety was difficult. The large and widespread increase in firearm purchases during the COVID-19 outbreak suggests that citizens on both sides of the political spectrum value owning a firearm for protection. With so many individuals purchasing firearms when their safety is threatened, finding common ground in the gun control debate may be more possible than ever.

\section{References}

American Medical Association (2020). Managing mental health during COVID-19. https://www.ama-assn. org/delivering-care/public-health/managing-mental-health-during-covid-19. Last accessed April 27,2020 .

Azrael, D., L. Hepburn, D. Hemenway, and M. Miller (2017). The stock and flow of us firearms: results from the 2015 national firearms survey. RSF: The Russell Sage Foundation Journal of the Social Sciences 3(5), 38-57.

Baker, S. R., N. Bloom, S. J. Davis, and S. J. Terry (2020). Covid-induced economic uncertainty. Technical report, National Bureau of Economic Research.

Balestra, S. (2018). Gun prevalence and suicide. Journal of Health Economics 61, 163-177.

Beckett, L. (2020). American purchasing record-breaking number of guns amid coronavirus. https://www. theguardian.com/world/2020/apr/01/us-gun-purchases-coronavirus-record.

Berger, T., C. Chen, and C. B. Frey (2018). Drivers of disruption? estimating the uber effect. European Economic Review 110, 197-210.

Bloom, N. (2009). The impact of uncertainty shocks. Econometrica r7(3), 623-685. 
Center for Responsive Politics (2020). Client Profile: National Rifle Assn. https://www.opensecrets.org/ federal-lobbying/clients/summary?cycle=2019\&id=d000000082. Last accessed May 1, 2020.

Depetris-Chauvin, E. (2015). Fear of obama: An empirical study of the demand for guns and the us 2008 presidential election. Journal of Public Economics 130, 66-79.

Depew, B. and I. D. Swensen (2019). The decision to carry the effect of crime on concealed-carry applications. Journal of Human Resources 54(4), 1121-1153.

Donnelly, S. (2001). The Day the FAA Stopped the World. Time.

Duggan, M. (2001). More guns, more crime. Journal of Political Economy 109(5), 1086-1114.

Duggan, M., R. Hjalmarsson, and B. A. Jacob (2011). The short-term and localized effect of gun shows: Evidence from california and texas. Review of Economics and Statistics 93(3), 786-799.

Edwards, G., E. Nesson, J. J. Robinson, and F. Vars (2018). Looking down the barrel of a loaded gun: The effect of mandatory handgun purchase delays on homicide and suicide. The Economic Journal 128(616), $3117-3140$.

Federal Bureau of Investigation (2018). Active Shooter Incidents from 2000 - 2018. https://www.fbi.gov/ file-repository/active-shooter-incidents-2000-2018.pdf. Last accessed May 1, 2020.

Federal Bureau of Investigation (2020). Total NICS Firearm Background Checks by State, November 30, 1998 - April 30, 2020. https://www.fbi.gov/file-repository/nics_firearm_checks_-_month_year_ by_state.pdf, Last accessed May 4, 2020.

Federal Election Commission (2020). Official Results of Federal Elections. https://transition.fec.gov/ pubrec/electionresults.shtml. Last accessed May 1, 2020.

Fisher, T., S. Frostenson, and L. Mihalik (2018). The gun lobby: See how much your representative gets. https://www.politico.com/interactives/2017/gun-lobbying-spending-in-america-congress/

Follman, M., G. Aronsen, and D. Pan (2020). A Guide to Mass Shootings in America. https://www. motherjones.com/politics/2012/07/mass-shootings-map/. Last accessed May 1, 2020.

Gius, M. (2019). The relationship between concealed carry permits and state-level crime rates. Applied Economics Letters, 1-3.

Gramlich, J. and K. Schaeffer $(2019,10)$. 7 Facts about Guns in the U.S. Technical report, Pew Research Center.

Gun Violence Archive (2020). General Methodology. https://www.gunviolencearchive.org/methodology. Last accessed May 1, 2020.

Gunnell, D., L. Appleby, E. Arensman, K. Hawton, A. John, N. Kapur, M. Khan, R. C. O'Connor, J. Pirkis, E. D. Caine, et al. (2020). Suicide risk and prevention during the covid-19 pandemic. The Lancet Psychiatry.

Hauser, W. and G. Kleck (2013). Guns and fear: a one-way street? Crime $\mathcal{E}$ Delinquency 59(2), 271-291.

Jefferson, T. (1776). The Virginia Constitution of 1776, Second Draft. https://founders.archives.gov/ documents/Jefferson/01-01-02-0161-0003

Kearney, M. S. and P. B. Levine (2015). Media influences on social outcomes: The impact of mtv's 16 and pregnant on teen childbearing. American Economic Review 105(12), 3597-3632.

Kleck, G., T. Kovandzic, M. Saber, and W. Hauser (2011). The effect of perceived risk and victimization on plans to purchase a gun for self-protection. Journal of Criminal Justice 39(4), 312-319.

Lang, M. (2013). Firearm background checks and suicide. The Economic Journal 123(573), 1085-1099.

Lang, M. (2016). State firearm sales and criminal activity: Evidence from firearm background checks. Southern Economic Journal 83(1), 45-68. 
Levine, P. B. and R. McKnight (2017). Firearms and accidental deaths: Evidence from the aftermath of the sandy hook school shooting. Science 358(6368), 1324-1328.

Lott, J. R. (2013). More guns, less crime: Understanding crime and gun control laws. University of Chicago Press.

Luca, M., D. Malhotra, and C. Poliquin (2017). Handgun waiting periods reduce gun deaths. Proceedings of the National Academy of Sciences 114(46), 12162-12165.

Luca, M., D. Malhotra, and C. Poliquin (2020). The impact of mass shootings on gun policy. Journal of Public Economics 181, Article 104083.

Mannix, R., L. Lee, and E. Fleegler (2020). Coronavirus disease 2019 (covid-19) and firearms in the united states: Will an epidemic of suicide follow? Annals of Internal Medicine.

Manski, C. F. and J. V. Pepper (2018). How do right-to-carry laws affect crime rates? coping with ambiguity using bounded-variation assumptions. Review of Economics and Statistics 100(2), 232-244.

Mervosh, S., D. Lu, and V. Swales (2020). See which states and cities have told residents to stay at home. New York Times.

Pfefferbaum, B. and C. S. North (2020). Mental health and the covid-19 pandemic. New England Journal of Medicine.

Pierre, J. M. (2019). The psychology of guns: risk, fear, and motivated reasoning. Palgrave Communications 5(1), 1-7.

Reger, M. A., I. H. Stanley, and T. E. Joiner (2020). Suicide mortality and coronavirus disease 2019 - a perfect storm? JAMA psychiatry.

Rushe, D. (2018). Why is the National Rifle Association so powerful? https://www.theguardian.com/ us-news/2017/nov/17/nra-gun-lobby-gun-control-congress

Stanford Geospatial Center (2018). Mass Shootings in America. https://library.stanford.edu/projects/ mass-shootings-america

Stephens-Davidowitz, S. (2014). The cost of racial animus on a black candidate: Evidence using google search data. Journal of Public Economics 118, 26-40.

Studdert, D. M., Y. Zhang, J. A. Rodden, R. J. Hyndman, and G. J. Wintemute (2017). Handgun acquisitions in California after two mass shootings. Annals of Internal Medicine 166(10), 698-706.

Tefft, N. (2011). Insights on unemployment, unemployment insurance, and mental health. Journal of Health Economics 30(2), 258-264.

United States Census Bureau (2020). Population and Housing Unit Estimates. https://www.census.gov/ programs-surveys/popest.html. Last accessed May 1, 2020.

Vitt, D. C., A. F. McQuoid, C. Moore, and S. Sawyer (2018). Trigger warning: the causal impact of gun ownership on suicide. Applied Economics 50(53), 5747-5765. 


\section{Appendix}

Table A.1: List of Mass Shootings Used in the Analysis

\begin{tabular}{lccc} 
Shooting Event & Month & Year & Fatalities \\
\hline Columbine, CO & April & 1999 & 13 \\
Virgina Tech, VA & April & 2007 & 32 \\
Binghamton, NY & April & 2009 & 13 \\
Fort Hood, TX & November & 2009 & 14 \\
Aurora, CO & July & 2012 & 12 \\
Sandy Hook, NJ & December & 2012 & 27 \\
Washington DC Navy Yard & September & 2013 & 12 \\
San Bernardino, CA & December & 2015 & 14 \\
Orlando, FL & June & 2016 & 49 \\
Las Vegas, NV & October & 2017 & 58 \\
Sutherland Springs, TX & November & 2017 & 26 \\
Parkland, FL & February & 2018 & 17 \\
Santa Fe, TX & May & 2018 & 10 \\
Pittsburgh, PA & October & 2018 & 11 \\
Thousand Oaks, CA & November & 2018 & 12 \\
Virgina Beach, VA & May & 2019 & 12 \\
El Paso, TX & August & 2019 & 23 \\
\hline
\end{tabular}

